\title{
Demographic and Clinical Profiles of Type 2 Diabetes Mellitus Patients Initiating Canagliflozin Versus DPP-4 Inhibitors in a Large U.S. Managed Care Population
}

\author{
Michael Grabner, PhD; Xiaomei Peng, MD, PhD; Caroline Geremakis, PhD; and Jay Bae, PhD
}

\begin{abstract}
BACKGROUND: Canagliflozin is the first sodium-glucose co-transporter-2 (SGLT-2) inhibitor-a new class of oral antidiabetic (OAD) medicationapproved for type 2 diabetes mellitus (T2DM) treatment in the United States. Approved less than 2 years ago, use of canagliflozin is largely uncharacterized.
\end{abstract}

OBJECTIVE: To investigate and compare baseline demographic, clinical, and economic characteristics of patients initiating canagliflozin and dipeptidyl peptidase-4 (DPP-4) inhibitors in the real-world setting.

METHODS: Using administrative claims data from a large, geographically diverse U.S. managed care organization, this retrospective study assessed adult T2DM patients (aged $\geq 18$ years) initiating treatment with canagliflozin or DPP-4 agents. Eligible patients had $\geq 1$ medical claim with a T2DM diagnosis and $\geq 1$ outpatient pharmacy claim for canagliflozin or a DPP-4 agent between January 1, 2011, and September 30, 2013. Patients with $\geq 1$ canagliflozin fill were selected first and assigned to the canagliflozin cohort following a hierarchical approach; the date of the earliest canagliflozin fill was defined as the index date. Remaining patients with DPP-4 fills were then assigned to the DPP-4 cohort, with the index date as the first DPP-4 fill. Only patients with at least 12 months of pre-index (baseline) enrollment were included. Patients with fills for their cohort-defining drug over 3 months before the index date were excluded in order to focus on new initiators. A subset of patients with $\geq 3$ months of continuous enrollment following their index dates was used to examine medication patterns after initiation. Patients with hyperglycemia; type 1 , gestational, or nonclinical diabetes; or diabetes with hyperosmolar coma were excluded. Demographic, clinical, and economic characteristics were assessed over baseline and compared using two-sample t-tests or chi-square/Fisher's exact tests. Multivariable logistic regression models were built to assess baseline factors associated with initiation of canagliflozin versus DPP-4.

RESULTS: Overall, 1,566 patients initiated canagliflozin, and 26,224 patients initiated DPP-4 treatment. Males constituted slightly more than $60 \%$ of each treatment group; mean age was approximately 55 years in each cohort. A significantly smaller proportion of canagliflozin patients $(41.3 \%)$ initiated treatment with endocrinologists compared with DPP-4 patients $(69.2 \%, P<0.001)$, and canagliflozin patients were more likely $(29.4 \%)$ to initiate treatment with a primary care physician compared with DPP-4 patients $(9.9 \%, P<0.001)$. Comorbidities were present more frequently in canagliflozin initiators: nephropathy $(10.6 \%$ vs. $7.0 \%)$, retinopathy $(10.4 \%$ vs. $7.5 \%)$, dyslipidemia ( $82.4 \%$ vs. $72.2 \%)$, and obesity $(24.9 \%$ vs. $15.6 \%$ ), respectively ( $P<0.001$ for all comparisons). The mean (SD) Quan-Charlson Comorbidity Index score was greater for canagliflozin, 1.05 (1.7), compared with DPP-4 initiators, 0.92 (1.6), $P=0.002$. Among the subset of patients with available hemoglobin A1c (A1c) results, a significantly smaller proportion of canagliflozin initiators (16.5\%) versus DPP-4 initiators $(26.7 \%)$ were at the $A 1 \mathrm{C}<7 \%$ treatment goal at baseline $(P<0.001)$. Among patients with 3 months follow-up, $89.2 \%$ of canagliflozin and $75.1 \%$ of DPP-4 initiators had $\geq 1$ fill for their index drugs over this time frame. Canagliflozin initiators had significantly greater baseline utilization of office visits, endocrinologist and outpatient services, and more prescription fills. Total diabetes-related medical costs at baseline $(\$ 3,025$ vs. $\$ 3,477$ for canagliflozin and DPP-4 initiators) were not significantly different, while mean diabetes-related pharmacy costs were higher in the canagliflozin group ( $\$ 4,037$ vs. $\$ 1,411, P<0.001)$. Regression analysis indicated that baseline insulin and glucagon-like peptide-1 use, as well as comorbid dyslipidemia and obesity, were significantly associated with the initiation of canagliflozin versus DPP-4 agents.

CONCLUSIONS: In this sample of commercially insured patients within a large managed care plan, canagliflozin was often initiated as secondor third-line therapy, with a relatively high share of patients receiving concomitant antidiabetic injectables, compared with DPP-4 initiators. Canagliflozin initiators had highly elevated A1c levels and were frequently diagnosed with other metabolic conditions. Baseline pharmacy utilization and costs were higher among canagliflozin patients. Future research is needed to assess real-world clinical outcomes after canagliflozin initiation, while taking these baseline differences into account.

J Manag Care Spec Pharm. 2015;21(12):1204-12

Copyright $\odot 2015$, Academy of Managed Care Pharmacy. All rights reserved.

\section{What is already known about this subject}

Type 2 diabetes mellitus, the largest segment of diagnosed diabetes, increases hyperglycemia risks, microvascular complications, and macrovascular events including stroke, myocardial infarction, and death.

Although numerous therapeutic options exist, the attainment of hemoglobin Alc (Alc) goals remains challenging-about half of all patients with diabetes attain the common Alc treatment goal of $<7.0 \%$.

Canagliflozin, which received marketing approval in the United States in 2013, has been shown in clinical trials to improve glycemic control and weight loss relative to life style changes alone and to improve Alc and glycemic levels, while improving blood pressure management compared with a number of other glucoselowering agents. 


\section{What this study adds}

In a real-world sample of patients, canagliflozin initiators tended to be sicker and have more comorbidities, concomitant medications, and greater use of health care resources, compared with dipeptidyl peptidase-4 initiators.

Canagliflozin patients were more likely to have elevated Alc levels before initiation and to have fills for insulin and glucagon-like peptide-1 receptor agonist agents.

The baseline differences found in this study need to be taken into account for comparisons of real-world outcomes and their use in health care decision making.

$\mathrm{T}$ ype 2 diabetes mellitus (T2DM) results from progressive defects in the production of insulin as well as from the response, generally resistance, to insulin secreted in the pancreas. ${ }^{1,2}$ Other contributory factors include ethnicity, family history, a sedentary lifestyle and obesity. ${ }^{1,3,4}$ Given the relationship between obesity and diabetes, other comorbidities, including hypertension, dyslipidemia, and nonalcoholic fatty liver disease, are typically more prevalent among patients diagnosed with diabetes. ${ }^{1,3,4}$ T2DM, the overwhelming majority (95\%) of all diagnosed diabetes, increases hyperglycemia risks as well as attendant microvascular complications and macrovascular events such as stroke, myocardial infarction, and death. ${ }^{1,2,5}$

One of the principal goals of diabetes management is to attain hemoglobin Alc (Alc) treatment goals and prevent the onset or decrease the rate of occurrence of microvascular conditions. ${ }^{2,6}$ Numerous treatment options are available for the management of T2DM, although for most patients, lifestyle changes, including healthy eating, weight control, and increased physical activity, are typically the first step. Unless there are clear contraindications, metformin monotherapy is prescribed, and if Alc targets are not attained after 3 months, 1 (or more) of several classes of agents could be added, such as sulfonylureas, thiazolidinediones, dipeptidyl peptidase-4 (DPP-4) inhibitors, glucagon-like peptide-1 (GLP-1) receptor agonists, or basal insulin. ${ }^{2,6}$ Despite the broad range of therapeutic options, the attainment of Alc goals among patients with diabetes remains challenging, with just slightly more than half $(52 \%)$ of diabetes patients attaining the common Alc goal of $<7.0 \%$.

In March 2013, the U.S. Food and Drug Administration (FDA) approved canagliflozin-the first sodium-glucose cotransporter-2 (SGLT-2) inhibitor-for use as an oral antidiabetic (OAD) for the treatment of T2DM in the United States. ${ }^{8-12}$ Canagliflozin is indicated as an add-on to lifestyle changes aimed at attaining glycemic control..$^{8,13}$ In clinical trials, patients receiving canagliflozin have been shown to achieve improved glycemic control and weight management versus diet, exercise, and other lifestyle changes, ${ }^{13,14}$ greater
Alc reduction versus glimepiride, ${ }^{15}$ better glycemic control and weight reduction than patients receiving sitagliptin, ${ }^{16}$ and improved blood pressure, body weight, and glycemic control compared with a range of blood glucose-lowering medications. ${ }^{17}$ Two other SGLT-2 inhibitors have been approved subsequently by the FDA-dapagliflozin and empagliflozin-in January and August 2014, respectively. ${ }^{18,19}$

SGLT-2 agents have a mechanism of action that is independent of insulin secretion and function by normalizing high blood glucose levels and maintaining the body's equilibrium. Acting as transporters that reabsorb glucose from the renal filtrate, SGLT-2 agents inhibit the loss of glucose in the urine as compared with other treatments that cause the renal excretion of glucose. , $^{8,-22}$ This novel pathway may render SGLT-2 agents particularly useful for advanced patients for whom other OADs have started to show diminished effectiveness. ${ }^{23}$

The purpose of this retrospective study was to examine the baseline demographic, clinical, and economic characteristics of commercially insured patients initiating canagliflozin using administrative claims. The real-world use of canagliflozin is not well characterized because of its relatively short time on the U.S. market. To assist in the interpretation of the findings on canagliflozin, a cohort of patients initiating DPP-4 inhibitors was also analyzed. DPP-4 agents are another relatively new and successful class of second/third-line OADs, first approved in the United States in 2006 and currently including 4 FDAapproved formulations (sitagliptin, saxagliptin, linagliptin, and alogliptin). ${ }^{24,25}$

\section{Methods}

\section{Data Source and Study Design}

This was a retrospective cohort study that employed administrative claims and electronic laboratory results from the HealthCore Integrated Research Database (HIRD) for the period from January 1, 2011, to September 30, 2013. A repository of more than 40 million researchable lives, the HIRD contains medical and pharmacy claims data originating in 14 geographically dispersed commercial health plans across the continental United States. Outpatient laboratory test results are directly available for a subset of patients who get tested at 2 large national laboratory service providers. Hierarchical selection was used to derive the final sample for analysis. The index date for patients with 1 or more fills for canagliflozin between January 1, 2012, and September 30, 2013, was defined as the date of the earliest outpatient pharmacy claim for canagliflozin (Generic Product Identifier [GPI] beginning with 2770). Among remaining patients, the date of the first prescription claim for any DPP-4 agent (GPI beginning with 2755, plus fixed-dose combinations) between January 1, 2012, and September 30, 2013, was defined as the index date. This nonexperimental study, which was exempt from institutional review board review, was fully compliant with applicable provisions of the 
Health Insurance Portability and Accountability Act. Patient confidentiality was maintained throughout, and all data remained anonymous; researchers had access to the relevant datasets after all individual patient identifiers were removed.

\section{Inclusion/Exclusion Criteria}

Patients were required to have $\geq 1$ medical claim indicating presence of T2DM (International Classification of Diseases, Ninth Revision, Clinical Modification [ICD-9-CM] diagnosis codes $250 . x 0$ or 250.x2) any time during the study period. Included patients were aged 18 years years or older on the index date, enrolled in a commercial health plan for the duration of the study, and had $\geq 12$ months (365 days) pre-index continuous medical and pharmacy enrollment (baseline period). To evaluate short-term medication use after initiation, a subsample of patients with $\geq 3$ months (92 days) of continuous medical and pharmacy enrollment was created (follow-up period). Patients with $\geq 1$ claim at any point during the study period with ICD9-CM diagnosis codes indicating type 1 diabetes, gestational/ neonatal diabetes, hyperglycemia (not otherwise specified), nonclinical diabetes, and diabetes with hyperosmolar coma were excluded from the study (see Appendix A for codes, available in online article). Patients with fills for their cohortdefining drugs over 3 months before the index date were also excluded in order to focus on new initiators.

\section{Patient Characteristics and Outcomes}

At baseline, demographic characteristics including age, gender, and geographic region were evaluated. Among the clinical characteristics evaluated at baseline were concomitant medication use including OADs, number of patients with $\geq 1$ hypoglycemic event (overall and stratified by inpatient and outpatient place setting), ${ }^{26}$ and chronic comorbidities (using ICD-9-CM codes; see Appendix A). Quan-Charlson Comorbidity Index (QCI) scores were also calculated at baseline. ${ }^{27}$ In the canagliflozin cohort, the average daily dose of the index medication was evaluated at first prescription and again at the 3-month follow-up. Concomitant medication use was also evaluated at follow-up. Laboratory results assessed at baseline included Alc, random blood glucose, serum creatinine, and estimated glomerular filtration rate (eGFR) using the chronic kidney disease epidemiology equation. ${ }^{28}$ These tests were assessed in subgroups based on availability of laboratory results in the HIRD. Additionally, mean Alc change between baseline and the 3-month follow-up was evaluated for patients receiving canagliflozin. All-cause and diabetes-related (defined as claims with ICD-9-CM codes of 250.xx) health care resource utilization and costs were evaluated for all patients at baseline. Resource utilization and costs were stratified by place of service (inpatient, emergency room, physician office visits, and other outpatient visits). Costs were adjusted to 2013 U.S. dollars using medical care price index information provided by the Bureau of Labor Statistics. ${ }^{29}$

\section{Statistical Analysis}

Descriptive statistics included means (standard deviation [SD]) and relative frequencies for continuous and categorical variables, respectively. Continuous variables were compared between canagliflozin and DPP-4 initiators with two-sample t-tests, while categorical variables were compared with chisquare tests or Fisher's exact tests, as appropriate. Multivariable logistic regression modeling was conducted with the dependent variable indicating canagliflozin versus DPP-4 initiation; covariates included key baseline demographic and clinical characteristics. The regression was applied to a subsample of patients with metformin use at baseline. Two models, one without and one with Alc at baseline (resulting in a smaller sample) were evaluated; the results for the larger sample without baseline Alc are presented as a Forest plot. Alpha was set a priori at 0.05 for statistical significance. All analyses were conducted using SAS version 9.2 (SAS Institute, Cary, NC).

\section{Results}

\section{Patient Disposition}

The database query identified 2,373 canagliflozin and 67,678 DPP-4 initiators who had $\geq 1$ medical claim for T2DM and $\geq 1$ index drug fill and satisfied the age and enrollment requirements. Removal of patients without the 3-month clean period and of those with claims for excluded diagnoses resulted in 1,566 canagliflozin and 26,224 DPP-4 initiators, as shown in Figure 1. A total of 472 canagliflozin and 22,562 DPP-4 initiators had at least 3 months of post-index health plan enrollment.

\section{Clinical and Demographic Characteristics at Baseline}

Mean age (SD) was 54 (8.5) years for canagliflozin and 55 (9.9) years for DPP-4 initiators. Approximately $61 \%$ of patients in both cohorts were male. The majority of patients were enrolled in midwestern and southern-based preferred provider organization health plans. Overall, 3.6\% of canagliflozin initiators, as opposed to $2.2 \%$ of DPP-4 initiators, had $\geq 1$ hypoglycemic event at baseline $(P<0.001)$; the proportions were similar $(0.5 \%)$ in the inpatient setting but significantly greater for canagliflozin patients $(3.2 \%)$ versus DPP-4 initiators $(1.8 \%)$ in the outpatient setting $(P<0.001)$. A significantly smaller proportion of patients initiating canagliflozin (41.3\%) received their index scripts from a specialist (endocrinologist) as compared with DPP-4 initiators (69.2\%, P<0.001). Also, a significantly larger proportion of patients (29.4\%) initiated canagliflozin therapy with a primary care physician (PCP) compared with DPP-4 initiators $(9.9 \%, P<0.001)$, as shown in Table 1 . Major diabetesrelated comorbidities were significantly more common among canagliflozin versus DPP-4 initiators: nephropathy (10.6 \% vs. $7.0 \%$ ), retinopathy ( $10.4 \%$ vs. $7.5 \%$ ), dyslipidemia ( $82.4 \%$ vs. $72.2 \%$ ), and obesity $(24.9 \%$ vs. $15.6 \%, P<0.001)$. The mean (SD) QCI score was greater among canagliflozin, 1.05 (1.7), as compared with DPP-4 initiators, 0.92 (1.6), $P=0.002$. 


\section{Step 1}

Patients with at least:

- 1 selected OAD fill (index date=date of first fill)

- 1 claim for T2DM during the study period

- 12 months of pre-index health plan enrollment

- Aged 18 years on index date

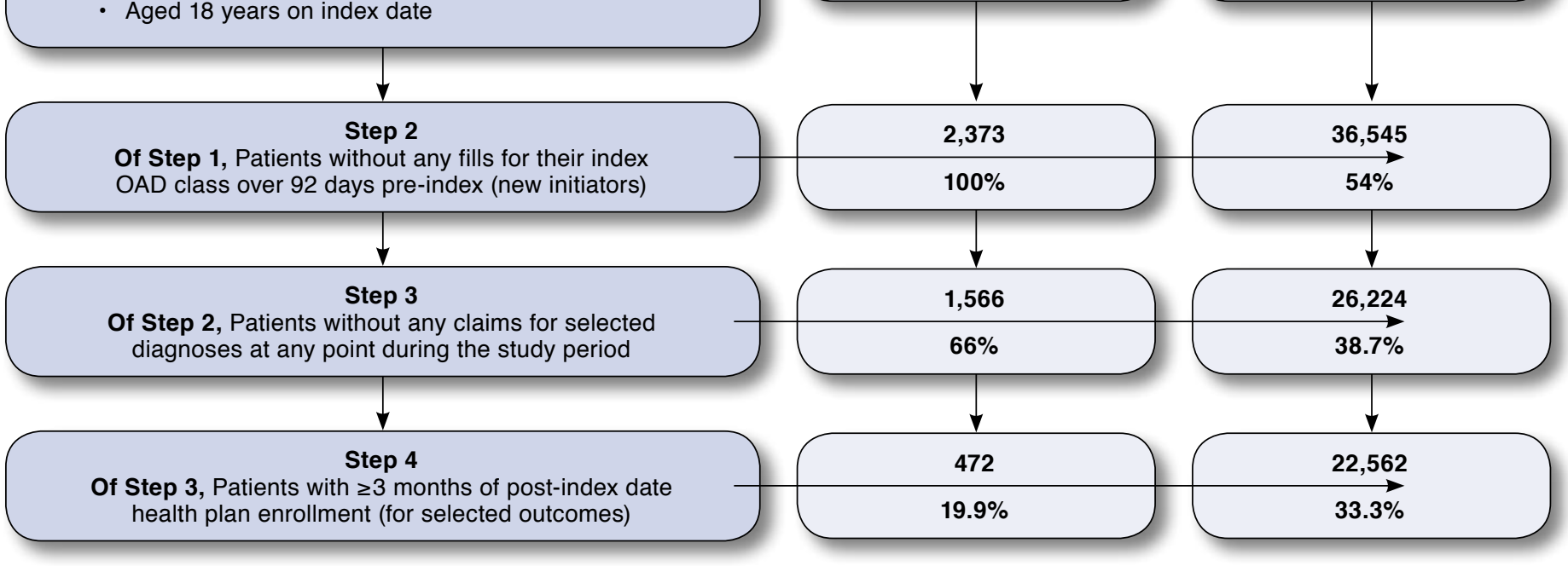

DPP-4 = dipeptidyl peptidase-4; $O A D=$ oral antidiabetic; T2DM = type 2 diabetes mellitus.

Alc values were available for approximately $30 \%$ of patients in each cohort. Among this subset, mean (SD) Alc values at baseline were $8.5 \%$ (1.7) for canagliflozin and 8.3\% (1.9) for DPP-4 initiators $(P=0.095)$. A significantly lower proportion of canagliflozin initiators (16.5\%) versus DPP-4 initiators (26.7\%) were at the Alc $<7 \%$ treatment goal at baseline $(P<0.001)$. Progressively greater proportions of patients initiated canagliflozin relative to DPP-4 treatment at Alc levels $\geq 7 \%$ as shown in Figure 2. Mean values and proportions of patients achieving targets for random blood glucose, serum creatinine, and eGFR were similar across the 2 cohorts. Among a subsample of canagliflozin patients with Alc levels available at baseline and follow-up ( $\mathrm{n}=31$ ), the mean (SD) change in Alc (post minus pre) was -0.93 (1.81), with a baseline mean (SD) of 8.6 (1.69) and a follow-up mean (SD) of 6.4 (1.81). The largest reductions were observed in patients with Alc $\geq 9 \%$ at baseline $(n=10)$.

\section{Medication Treatment Patterns at Baseline and Follow-up}

Approximately two thirds of patients in each initiating cohort received metformin, and a significantly larger proportion of canagliflozin initiators (45.6\%) received sulfonylureas compared with DPP-4 initiators $(37.2 \%)$ at baseline $(P<0.001)$.
Significantly larger proportions of canagliflozin relative to DPP-4 initiators were treated with GLP-1 receptor agonists (31.0\% vs. $4.3 \%)$ and insulin (24.7\% vs. $9.1 \%)$, respectively $(P<0.001)$. As indicated in Table 2 , the proportions of patients who received 0,1 , or 2 classes of OADs at baseline were similar across cohorts, while slightly more canagliflozin patients had 3 or more classes. The proportions of patients using any dyslipidemic, cardiovascular disease, or antihypertensive medication were significantly greater among canagliflozin relative to DPP-4 initiators $(P<0.001)$.

Among a subset of patients with 3 months of follow-up, the average daily dose for canagliflozin initiators was 166.1 milligrams (mg) at index, increasing to $187.3 \mathrm{mg}$ at the 3-month follow-up (although $89 \%$ of patients did not experience any up-titration). As shown in Table 2, at the 3-month followup significantly larger proportions of canagliflozin initiators relative to DPP-4 initiators were receiving metformin (53.2\% vs. $36.7 \%$ ), any insulin (18.0\% vs. 9.3\%), and any GLP-1 receptor agonist $(20.8 \%$ vs. $2.6 \%, P<0.001)$. Canagliflozin users also appeared more adherent than DPP-4 initiators based on the proportion of patients with $\geq 1$ fill of the index drug (89.2\% vs. $75.1 \%)$. 
TABLE 1 Baseline Demographics, Comorbidities, and Laboratory Values

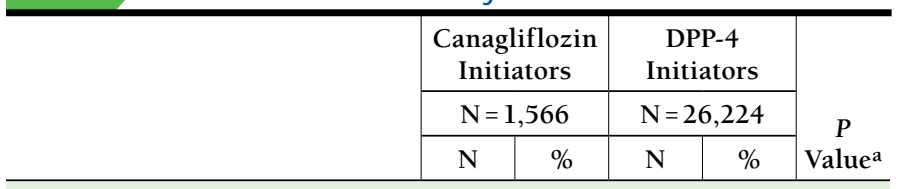

Baseline demographics

\begin{tabular}{|c|c|c|c|c|c|}
\hline Female & 602 & 38.4 & 10,356 & 39.5 & 0.409 \\
\hline Age, mean (SD) & 54.0 & 8.5 & 55.1 & 9.9 & $<0.001$ \\
\hline \multicolumn{6}{|c|}{ Prescribing/treating physician specialty ${ }^{b}$} \\
\hline Primary care physician & 460 & 29.4 & 2,595 & 9.9 & $<0.001$ \\
\hline Endocrinologist & 647 & 41.3 & 18,147 & 69.2 & $<0.001$ \\
\hline Other/unknown & 459 & 29.3 & 5,482 & 20.9 & $<0.001$ \\
\hline \multicolumn{6}{|l|}{ Baseline comorbidities } \\
\hline $\begin{array}{l}\text { Quan-Charlson Comorbidity } \\
\text { Index score, mean (SD) }\end{array}$ & 1.05 & 1.7 & 0.92 & 1.6 & 0.002 \\
\hline Neuropathy & 69 & 4.4 & 810 & 3.1 & 0.004 \\
\hline Nephropathy & 166 & 10.6 & 1,844 & 7.0 & $<0.001$ \\
\hline Retinopathy & 163 & 10.4 & 1,972 & 7.5 & $<0.001$ \\
\hline Gastrointestinal disease & 232 & 14.8 & 4,000 & 15.3 & 0.639 \\
\hline Dyslipidemia & 1,291 & 82.4 & 18,921 & 72.2 & $<0.001$ \\
\hline Hypertension & 1,200 & 76.6 & 18,603 & 70.9 & $<0.001$ \\
\hline Obesity & 390 & 24.9 & 4,099 & 15.6 & $<0.001$ \\
\hline
\end{tabular}

Laboratory results at baseline

\begin{tabular}{l|r|r|r|r|r}
\hline Alc, with $\geq 1$ test result & 521 & 33.3 & 7,643 & 29.2 & 0.001 \\
\hline $\begin{array}{l}\text { Most recent lab result (\%), mean } \\
(\mathrm{SD})\end{array}$ & 8.45 & 1.65 & 8.31 & 1.93 & 0.095 \\
\hline Patients with Alc $\leq 7 \%$ & 86 & 16.5 & 2,037 & 26.7 & $<0.001$ \\
\hline $\begin{array}{l}\text { Random blood glucose, with } \geq 1 \\
\text { test result }\end{array}$ & 574 & 36.7 & 8,053 & 30.7 & $<0.001$ \\
\hline $\begin{array}{l}\text { Most recent lab result (mg/dL), } \\
\text { mean (SD) }\end{array}$ & 176.03 & 64.75 & 174.63 & 72.31 & 0.653 \\
\hline Patients with RBG $<180 \mathrm{mg} / \mathrm{dL}$ & 352 & 61.3 & 5,103 & 63.4 & 0.327 \\
\hline $\begin{array}{l}\text { Serum creatinine, with } \geq 1 \text { test } \\
\text { result }\end{array}$ & 597 & 38.1 & 8,361 & 31.9 & $<0.001$ \\
\hline $\begin{array}{l}\text { Most recent lab result (mg/dL), } \\
\text { mean (SD) }\end{array}$ & 0.89 & 0.21 & 0.90 & 0.30 & 0.220 \\
\hline $\begin{array}{l}\text { Patients with serum creatinine } \\
0.6-1.3 \mathrm{mg} / \mathrm{dL}\end{array}$ & 532 & 89.1 & 7,336 & 87.7 & 0.085 \\
\hline eGFR, with $\geq 1$ test result & 597 & 38.1 & 8,361 & 31.9 & $<0.001$ \\
\hline $\begin{array}{l}\text { Most recent lab result (mL/ } \\
\text { min/l.73 m }{ }^{2} \text { ), mean (SD) }\end{array}$ & 94.13 & 11.96 & 93.72 & 12.76 & 0.243 \\
\hline $\begin{array}{l}\text { Patients with eGFR } \geq 60 \mathrm{~mL} / \\
\text { min/l.73 m }{ }^{2}\end{array}$ & 559 & 94.6 & 8,187 & 97.9 & 0.070 \\
\hline
\end{tabular}

ap values are from two-sample t-tests for continuous variables and from chi-squarel Fisher's exact tests for categorical variables.

bPrimary care physician includes family/general, internal medicine, and geriatrics. Alc = hemoglobin Alc; DPP-4 = dipeptidyl peptidase-4; eGFR=estimated glomerular filtration rate; $\mathrm{mg} / \mathrm{dL}=$ milligram per deciliter; $\mathrm{mL} / \mathrm{min}=$ milliliter per minute; $R B G=$ random blood glucose; $S D=$ standard deviation.

\section{Baseline Diabetes-Related Health Care Utilization and Costs}

Significantly larger proportions of canagliflozin relative to DPP-4 initiators had $\geq 1$ physician office visit (96.3\% vs. 89.1\%; mean 3.7 vs. 2.8), as well as $\geq 1$ endocrinologist visit ( $28.0 \%$ vs. 8.1\%; mean 0.7 vs. 0.2 ) at baseline, along with at least 1 other

\section{FIGURE 2 Distribution of Hemoglobin A1C at Baseline}

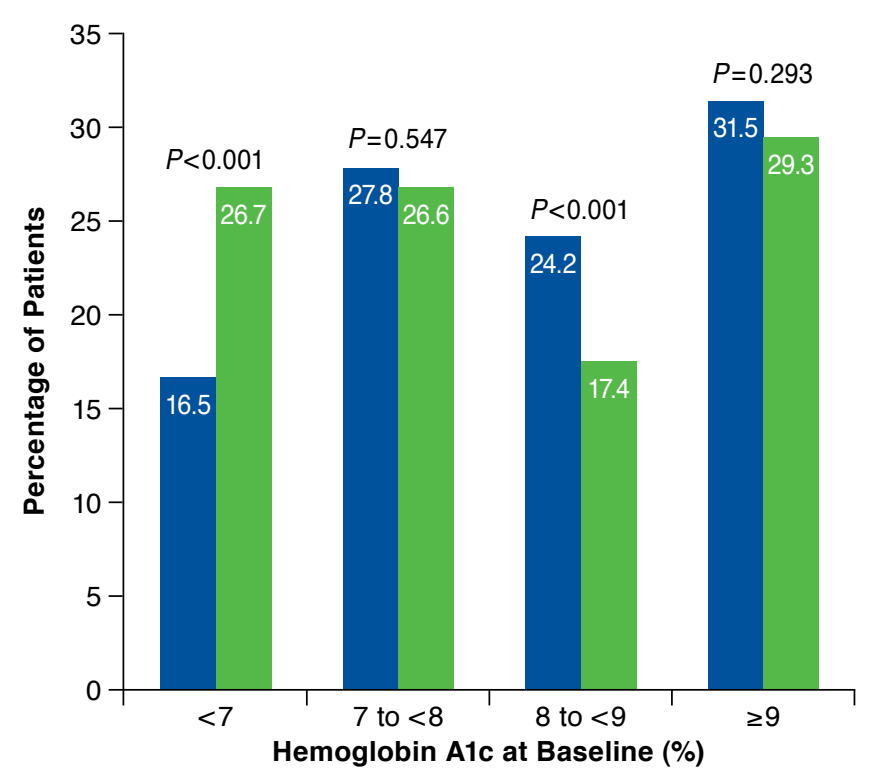

Canagliflozin initiators DPP-4 initiators

Note: P values are from chi-square tests.

DPP-4 = dipeptidyl peptidase-4.

outpatient visit (88.2\% compared with $79.6 \%$; mean 2.6 vs. 2.1, $P<0.001$ ). The use of emergency room and inpatient services was low in both cohorts, and differences were less pronounced. Canagliflozin initiators were significantly more likely to have $\geq 1$ pharmacy fill and had a mean 12.4 fills, compared with 6.8 for DPP-4 patients $(P<0.001)$, as shown in Table 3. While the mean costs associated with physician office visits were significantly higher for canagliflozin initiators compared with DPP-4 patients ( $\$ 506$ vs. $\$ 359, P<0.001$ ), there was no significant difference in total medical costs $(\$ 3,025$ vs. $\$ 3,477, P=0.197)$. This may be due to the trend towards higher inpatient costs among DPP-4 patients, which, while not statistically significantly higher, appear to counterbalance the higher office visit costs in the canagliflozin cohort. The mean pharmacy costs were significantly greater for canagliflozin initiators $(\$ 4,037 \mathrm{vs}$. $\$ 1,411, P<0.001)$. On average, canagliflozin initiators also had significantly greater combined medical and pharmacy costs ( $\$ 7,063$ vs. $\$ 4,888, P<0.001)$. All-cause utilization and costs at baseline for the 2 cohorts show similar patterns and are provided in Appendix B (available in online article).

\section{Multivariable Analysis}

Regression analysis of a subgroup of patients with $\geq 1$ metformin fill at baseline ( $n=1,005$ canagliflozin, $n=16,431$ 


\section{TABLE 2 Baseline and Follow-up Medication} Treatment Patterns

\begin{tabular}{|c|c|c|c|c|c|}
\hline & \multirow{2}{*}{\multicolumn{2}{|c|}{\begin{tabular}{|c|}
$\begin{array}{c}\text { Canagliflozin } \\
\text { Initiators }\end{array}$ \\
$\mathrm{N}=1,566$ \\
\end{tabular}}} & \multirow{2}{*}{\multicolumn{2}{|c|}{$\begin{array}{c}\begin{array}{c}\mathrm{DPP}-4 \\
\text { Initiators }\end{array} \\
\mathrm{N}=26,224\end{array}$}} & \multirow{3}{*}{$\begin{array}{c}P \\
\text { Value }^{\mathrm{a}}\end{array}$} \\
\hline & & & & & \\
\hline & $\mathrm{N}$ & $\%$ & $\mathrm{~N}$ & $\%$ & \\
\hline \multicolumn{6}{|l|}{ Baseline medication use, with $\geq 1$ fill } \\
\hline Metformin & 1,005 & 64.2 & 16,431 & 62.7 & 0.227 \\
\hline Thiazolidinediones & 287 & 18.3 & 5,053 & 19.3 & 0.358 \\
\hline Sulfonylureas & 714 & 45.6 & 9,745 & 37.2 & $<0.001$ \\
\hline DPP-4 inhibitors & 394 & 25.2 & 4,180 & 15.9 & $<0.001$ \\
\hline Meglitinides & 54 & 3.5 & 417 & 1.6 & $<0.001$ \\
\hline GLP-1 receptor agonists & 485 & 31.0 & 1,115 & 4.3 & $<0.001$ \\
\hline Liraglutide & 337 & 21.5 & 654 & 2.5 & $<0.001$ \\
\hline Exenatide & 58 & 3.7 & 459 & 1.8 & $<0.001$ \\
\hline Bydureon & 132 & 8.4 & 64 & 0.2 & $<0.001$ \\
\hline Insulin & 387 & 24.7 & 2,381 & 9.1 & $<0.001$ \\
\hline Basal only & 237 & 15.1 & 1,737 & 6.6 & $<0.001$ \\
\hline Basal-bolus & 133 & 8.5 & 547 & 2.1 & $<0.001$ \\
\hline Any dyslipidemic medication & 1,154 & 73.7 & 16,941 & 64.6 & $<0.001$ \\
\hline Any CVD medication ${ }^{b}$ & 1,064 & 67.9 & 15,829 & 60.4 & $<0.001$ \\
\hline Any antihypertensive medication & 1,140 & 72.8 & 17,144 & 65.4 & $<0.001$ \\
\hline \multicolumn{6}{|c|}{ Number of OAD classes during baseline } \\
\hline 0 classes & 463 & 29.6 & 8,168 & 31.2 & 0.189 \\
\hline 1 class & 863 & 55.1 & 14,209 & 54.2 & 0.475 \\
\hline 2 classes & 224 & 14.3 & 3,731 & 14.2 & 0.933 \\
\hline $3+$ classes & 16 & 1.0 & 116 & 0.4 & 0.001 \\
\hline $\begin{array}{l}\text { Follow-up medication use, with } \\
\geq 1 \text { fillc }\end{array}$ & \multicolumn{2}{|c|}{$\begin{array}{c}\text { Subgroup } \\
\mathrm{n}=472\end{array}$} & \multicolumn{2}{|c|}{$\begin{array}{l}\text { Subgroup } \\
\mathrm{n}=22,562\end{array}$} & \\
\hline Study (index) drug & 421 & 89.2 & 16,934 & 75.1 & $<0.001$ \\
\hline Metformin & 251 & 53.2 & 8,272 & 36.7 & $<0.001$ \\
\hline Thiazolidinediones & 54 & 11.4 & 1,623 & 7.2 & $<0.001$ \\
\hline Sulfonylureas & 165 & 35.0 & 6,619 & 29.3 & 0.008 \\
\hline DPP-4 inhibitors & 157 & 33.3 & 16,934 & 75.1 & $<0.001$ \\
\hline Meglitinides & 12 & 2.5 & 268 & 1.2 & 0.008 \\
\hline GLP-1 receptor agonists & 98 & 20.8 & 586 & 2.6 & $<0.001$ \\
\hline Insulin & 85 & 18.0 & 2,102 & 9.3 & $<0.001$ \\
\hline Any dyslipidemic medication & 293 & 62.1 & 12,648 & 56.1 & 0.009 \\
\hline Any CVD medication ${ }^{b}$ & 270 & 57.2 & 11,678 & 51.8 & 0.019 \\
\hline Any antihypertensive medication & 302 & 64.0 & 12,738 & 56.5 & 0.001 \\
\hline
\end{tabular}

aP values are from two-sample t-tests for continuous variables and from chi-square tests for categorical variables.

${ }^{b} \mathrm{CVD}$ medications include thrombolytics, nitroglycerines, clot preventing drugs, and antiplatelets.

'Assessed over a 3-month time frame from index date in a subsample of patients with $\geq 3$ months continuous enrollment after index date.

$C V D=$ cardiovascular disease; DPP-4 = dipeptidyl peptidase $-4 ;$ GLP-1 = glucagonlike peptide-1; $O A D=$ oral antidiabetic

DPP-4) identified factors that were significantly associated with the initiation of canagliflozin versus DPP-4 treatment as shown in Figure 3 (model c-statistic $=0.77$ ). Key baseline characteristics included the use of insulin (odds ratio $[\mathrm{OR}]=2.06$; 95\% confidence interval $[\mathrm{CI}]=1.72-2.45 ; \mathrm{P}<0.001$ ) and GLP-1 receptor agonists $(\mathrm{OR}=8.90 ; 95 \% \mathrm{CI}=7.60-10.41$;
TABLE 3 Diabetes-Related Health Care Utilization and Costs at Baseline

\begin{tabular}{|c|c|c|c|c|c|}
\hline & \multirow{2}{*}{\multicolumn{2}{|c|}{\begin{tabular}{|c|}
$\begin{array}{c}\text { Canagliflozin } \\
\text { Initiators }\end{array}$ \\
$\mathrm{N}=1,566$
\end{tabular}}} & \multirow{2}{*}{\multicolumn{2}{|c|}{$\begin{array}{c}\begin{array}{c}\text { DPP-4 } \\
\text { Initiators }\end{array} \\
\mathrm{N}=26,224\end{array}$}} & \multirow{3}{*}{$\begin{array}{c}P \\
\text { Value }^{\mathrm{a}}\end{array}$} \\
\hline & & & & & \\
\hline & $\mathrm{N}$ & $\%$ & $\mathrm{~N}$ & $\%$ & \\
\hline \multicolumn{6}{|l|}{ Annual health care utilization } \\
\hline Office visits, with $\geq 1$ visit & 1,508 & 96.3 & 23,377 & 89.1 & $<0.001$ \\
\hline Office visits, mean (SD) & 3.7 & 2.5 & 2.8 & 2.2 & $<0.001$ \\
\hline $\begin{array}{l}\text { Endocrinologist visits, with } \geq 1 \\
\text { visit }^{b}\end{array}$ & 438 & 28.0 & 2,128 & 8.1 & $<0.001$ \\
\hline Endocrinologist visits, mean (SD)b & 0.7 & 1.3 & 0.2 & 0.7 & $<0.001$ \\
\hline $\begin{array}{l}\text { Other outpatient visits, with } \geq 1 \\
\text { visit }^{c}\end{array}$ & 1,381 & 88.2 & 20,866 & 79.6 & $<0.001$ \\
\hline Other outpatient visits, mean (SD)c & 2.6 & 2.3 & 2.1 & 2.2 & $<0.001$ \\
\hline $\begin{array}{l}\text { Emergency room visits, with } \geq 1 \\
\text { visit }\end{array}$ & 164 & 10.5 & 2,264 & 8.6 & 0.012 \\
\hline Emergency room visits, mean (SD) & 0.1 & 0.4 & 0.1 & 0.4 & 0.075 \\
\hline Inpatient visits, with $\geq 1$ visit & 108 & 6.9 & 2,207 & 8.4 & 0.035 \\
\hline Inpatient visits, mean (SD) & 0.1 & 0.4 & 0.1 & 0.4 & 0.127 \\
\hline \multicolumn{6}{|l|}{ Annual pharmacy utilization } \\
\hline ith $\geq 1$ fill & 1,497 & 95.6 & 22,415 & 85.5 & $<0.001$ \\
\hline Pharmacy dispensing, mean (SD) & 12.4 & 8.0 & 6.8 & 5.9 & $<0.001$ \\
\hline \multicolumn{6}{|c|}{ Annual health care costs per patient, 2013 USD } \\
\hline Office visits, mean (SD) & 506 & 1,340 & 359 & 470 & $<0.001$ \\
\hline Other outpatient visits, mean $(\mathrm{SD})^{\mathrm{c}}$ & 780 & 3,226 & 719 & 3,098 & 0.445 \\
\hline Emergency room visits, mean (SD) & 248 & 1,057 & 194 & 1,009 & 0.040 \\
\hline Inpatient visits, mean (SD) & 1,491 & 10,539 & 2,206 & 12,785 & 0.030 \\
\hline Total medical costs, mean (SD) & 3,025 & 11,729 & 3,477 & 13,556 & 0.197 \\
\hline Total medical costs, median & 704 & - & 528 & - & - \\
\hline Pharmacy costs, mean (SD) & 4,037 & 4,701 & 1,411 & 2,390 & $<0.001$ \\
\hline Pharmacy costs, median & 3,210 & - & 267 & - & - \\
\hline $\begin{array}{l}\text { Total medical + pharmacy costs, } \\
\text { mean (SD) }\end{array}$ & 7,063 & 12,514 & 4,888 & 13,791 & $<0.001$ \\
\hline $\begin{array}{l}\text { Total medical + pharmacy costs, } \\
\text { median }\end{array}$ & 4,752 & - & 1,587 & - & - \\
\hline \multicolumn{6}{|c|}{$\begin{array}{l}\text { aP values are from two-sample t-tests for continuous variables and from chi-squ } \\
\text { tests for categorical variables. } \\
\text { bEndocrinologist visits that take place in an office setting. } \\
\text { cother outpatient facility visits such as clinics, ordered lab tests, and imaging. } \\
\text { DPP-4 = dipeptidyl peptidase-4; SD=standard deviation; USD =U.S. dollars. }\end{array}$} \\
\hline
\end{tabular}

$P<0.001)$ and the presence of comorbid conditions such as neuropathy $(\mathrm{OR}=1.30 ; 95 \% \mathrm{CI}=1.01-1.66, P=0.039)$, retinopathy $(\mathrm{OR}=1.30 ; 95 \% \mathrm{CI}=1.03-1.64 ; P=0.030)$, dyslipidemia (OR $=1.48 ; 95 \% \mathrm{CI}=1.23-1.79 ; P<0.001)$, and obesity $(\mathrm{OR}=1.54 ; 95 \% \mathrm{CI}=1.31-1.81, \mathrm{P}<0.001)$. In a subgroup of patients with Alc available at baseline ( $\mathrm{n}=310$ canagliflozin, $\mathrm{n}=4,874$ DPP-4), a second logistic regression model (model c-statistic $=0.81)$ suggested that baseline Alc $\geq 7 \%$ is associated with an increase in the likelihood of initiating canagliflozin $(\mathrm{OR}=1.80 ; 95 \% \mathrm{CI}=1.26-2.55 ; \mathrm{P}=0.001)$ after adjusting for other patient demographic and clinical characteristics. 


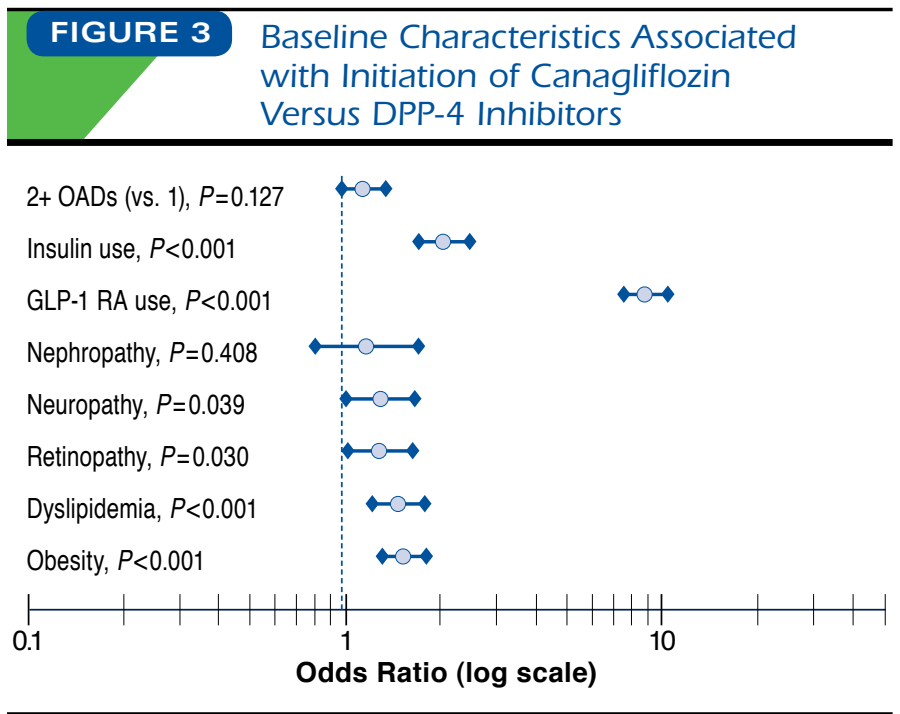

DPP-4 = dipeptidyl peptidase-4; GLP-1 = glucagon-like peptide-1; OAD = oral antidiabetic; $R A=$ receptor agonist.

\section{Discussion}

This is one of the first studies in the United States to present real-world information on the clinical and demographic characteristics as well as associated health care utilization and cost patterns of T2DM patients initiating canagliflozin versus DPP-4 inhibitors. One previously published study also examined baseline clinical and demographic characteristics of patients with T2DM who initiated canagliflozin in a different U.S. managed care setting. ${ }^{30}$ While this recent study did not present results for a comparison cohort, its findings regarding the characteristics of canagliflozin initiators are consistent with our findings.

In the time period investigated in this study, roughly 17 times the number of patients in the study sample initiated treatment with DPP-4 agents relative to canagliflozin. The overwhelming difference may be attributed foremost to the comparatively recent approval of canagliflozin (March 2013) compared with DPP-4 agents, which were marketed in the United States since 2006 beginning with the approval of sitagliptin..$^{24}$ Furthermore, unlike canagliflozin-the first agent in the SGLT-2 inhibitor class to be approved-DPP-4 agents have a long and familiar track record, as well as more efficacy and safety data. The approval of 3 new DPP-4 agents in the United States since sitagliptin became available demonstrates how well the DPP-4 class is established in the marketplace. ${ }^{25}$

The health plans in this study cover pharmacy costs for canagliflozin and DPP-4 drugs but require prior authorization, including step therapy and quantity limits; canagliflozin also requires higher patient copay compared with preferred
DPP-4 agents. Approval for the use of canagliflozin requires that patients have not achieved glycemic control with titrated metformin and a DPP-4 agent; approval for the use of a DPP-4 agent itself requires that patients have not achieved glycemic control with titrated metformin (unless contraindicated). There are several inexpensive existing OADs that have known and acceptable safety records; therefore, at this time it does not seem likely that patients, payers, or providers would consider using canagliflozin as first-line therapy but more likely would consider it as second or third tier or as combination treatment. ${ }^{23}$

In this study, a wider range of concomitant medications was used by canagliflozin initiators compared with DPP-4 initiators. In particular, insulin and GLP-1 receptor agonists were much more prevalent in canagliflozin initiators. Use of other concomitant medications, including metformin, sulfonylureas, dyslipidemic agents, antihypertensives, and cardiovascular disease medications, was also notably high. This could be a result of patient difficulties in reaching treatment goals, patient willingness to switch to other agents for better control of diabetes, and/or the attractiveness of a new class of agents with an entirely different mechanism of action.

Relative to patients initiating DPP-4 therapy, a significantly smaller proportion of study patients initiating canagliflozin were treated by endocrinologists, while a larger share initiated treatment with a PCP. The canagliflozin initiators used a broad range of OADs during the baseline period and seemed willing to change agents in hopes of improving their Alc levels. This could also be an indication that they were reluctant to start or continue treatment with injectables, which are more often prescribed by endocrinologists. . $^{31,32}$

Patients initiating canagliflozin appeared to have more advanced T2DM and generally lower health status than patients initiating DPP-4 agents. Patients initiating canagliflozin had a higher mean QCI score and proportionately more microvascular comorbidities, as well as dyslipidemia and obesity, which signal more cardiovascular complications. A treatment regimen that acts differently from therapies tried in the past could have some appeal to patients interested in finding new, more effective ways to control Alc, blood pressure, and especially weight, which canagliflozin is associated with. ${ }^{13-17}$

That canagliflozin initiators were less healthy than the DPP-4 initiators is also indicated by the significantly smaller proportion of canagliflozin patients who were at Alc treatment goals at baseline. In fact, patients initiated canagliflozin in progressively greater proportions than DPP-4 patients at higher Alc levels. Multivariable modeling suggested that signs of more severe illness (such as prior insulin and GLP-1 treatments and microvascular complications) were linked significantly to initiation of canagliflozin in comparison with DPP-4 agents. 
Overall, canagliflozin initiators had greater baseline use of office visits and endocrinologist and outpatient services and more prescription fills, which is consistent with more progressed disease. While mean total medical costs for the 2 patient groups were not significantly different, prescription costs and total expenditures on medical plus pharmacy services were greater for patients who initiated canagliflozin. These clinical and economic differences will need to be taken into account in future estimates of effectiveness, cost-effectiveness, and budget impact of canagliflozin using real-world data.

\section{Limitations}

This observational study relied exclusively on secondary data, which were repurposed for research from the original transactional functions. As a result, these findings must be approached with caution and confined to the parameters explored by the study. The sample was selected from a large managed care repository, and while the study population was reflective of working-age diabetes patients in commercial health plans across much of the continental United States, the results may not be generalizable to patients enrolled in different types of health plans or outside the United States, where health care delivery follows different rules. Claims databases, such as the HIRD used in this study, do not typically provide information on race and ethnicity nor do they include risk factors such as family history, smoking status, body mass index, diet, exercise regimen, or socioeconomic status-all of which could substantively influence outcomes. Administrative data are subject to miscoding or missing entries, and it is possible that the disease codes in the database used to identify conditions may not correspond entirely to the true presence of disease, since codes are entered by health care providers for the purpose of insurance billing. Furthermore, presence of a claim for a filled prescription does not indicate that the medication was consumed or that it was taken as prescribed. Laboratory results were available only for a subset of patients who completed testing at 2 large national reference laboratories, which provide between $20 \%-50 \%$ of outpatient diagnostic testing on a state-by-state basis. The recent approval of SGLT-2 inhibitors precluded the use of in-class comparators and only allowed for a 3-month follow-up period for canagliflozin. This limited the ability to identify any emerging trends or changes in treatment patterns, as well as conducting a more comprehensive assessment of postinitiation outcomes. It is possible that the early initiators of canagliflozin examined in the current study may differ in their characteristics from patients who started treatment more recently; canagliflozin is also currently subject to stricter prior authorization requirements and higher copays compared with DPP-4 agents. It would be interesting to revisit this population in future research to investigate potential changes over time as the market evolves.

\section{Conclusions}

In this sample of commercially insured patients associated with a large managed care plan, canagliflozin was often initiated as a second- or third-line therapy, with a relatively high share of patients receiving concomitant antidiabetic injectables, compared with patients initiating DPP-4 agents. Canagliflozin initiators also had highly elevated Alc levels prior to initiation and were frequently diagnosed with other metabolic syndrome conditions. Future research is needed to examine changes in treatment patterns and real-world clinical outcomes after canagliflozin initiation, especially in comparison with other treatment alternatives, while taking the observed baseline differences into account.

\section{Authors}

MICHAEL GRABNER, PhD, is Associate Director, Industry Sponsored Research, and CAROLINE GEREMAKIS, PhD, is Senior Researcher, HealthCore, Wilmington, Delaware. XIAOMEI PENG, $M D, P h D$, is Research Scientist, and JAY BAE, PhD, is Principal Research Scientist, Eli Lilly and Company, Indianapolis, Indiana.

AUTHOR CORRESPONDENCE: Michael Grabner, PhD, Associate Director, Industry Sponsored Research, HealthCore, 123 Justison St., Ste. 200, Wilmington, DE 19801. Tel.: 530.400.5978;

Fax: 302.230.2020; E-mail: mgrabner@healthcore.com.

\section{DISCLOSURES}

This study was funded by Eli Lilly and Company. Grabner and Geremakis are employees of HealthCore, an independent research organization that received funding from Eli Lilly and Company for the conduct of the study. Peng and Bae are employees of Eli Lilly and Company.

All authors contributed equally to the study design, interpretation of data, and writing and revision of the manuscript. Grabner and Geremakis collected the data.

\section{ACKNOWLEDGMENTS}

The authors thank Bernard B. Tulsi, MSc, HealthCore, for providing writing and editorial support for this article.

\section{REFERENCES}

1. Centers for Disease Control and Prevention. National diabetes fact sheet: national estimates and general information on diabetes and prediabetes in the United States, 2011. Atlanta, GA: U.S. Department of Health and Human Services, Centers for Disease Control and Prevention, 2011. Available at: http:// www.cdc.gov/diabetes/pubs/pdf/ndfs_2011.pdf. Accessed October 22, 2015.

2. Inzucchi SE, Bergenstal RM, Buse JB, et al. Management of hyperglycemia in type 2 diabetes: a patient-centered approach: position statement of the American Diabetes Association (ADA) and the European Association for the Study of Diabetes (EASD). Diabetes Care. 2012;35(6):1364-79. 
3. Centers for Disease Control and Prevention. National diabetes statistics report: estimates of diabetes and its burden in the United States, 2014. Atlanta, GA: U.S. Department of Health and Human Services; 2014. Available at: http:// www.cdc.gov/diabetes/pubs/statsreport14/national-diabetes-report-web.pdf. Accessed November 3, 2015

4. Flegal KM, Carroll MD, Ogden CL, Curtin LR. Prevalence and trends in obesity among U.S. adults, 1999-2008. JAMA. 2010;303(3):235-41.

5. Roger VL, Go AS, Lloyd-Jones DM, et al. Heart disease and stroke statistics-2012 update: a report from the American Heart Association. Circulation. 2012;125(1):e2-e220.

6. American Diabetes Association. Executive summary: Standards of medical care in diabetes-2014. Diabetes Care. 2014;37(Suppl 1):S5-S13.

7. Ali MK, Bullard KM, Saaddine JB, Cowie CC, Imperatore G, Gregg EW. Achievement of goals in U.S. diabetes care, 1999-2010. N Engl J Med. 2013;368(17):1613-24

8. Invokana (canagliflozin) tablets, for oral use. Janssen Pharmaceuticals. Revised September 2015. Available at: https://www.invokanahcp.com/ prescribing-information.pdf. Accessed October 22, 2015.

9. Babu A. Canagliflozin for the treatment of type 2 diabetes. Drugs Today (Barc). 2013:49(6):363-76

10. Bhatia J, Gamad N, Bharti S, Arya DS. Canagliflozin-current status in the treatment of type 2 diabetes mellitus with focus on clinical trial data. World J Diabetes. 2014;5(3):399-406.

11. Devineni D, Morrow L, Hompesch M, et al. Canagliflozin improves glycaemic control over 28 days in subjects with type 2 diabetes not optimally controlled on insulin. Diabetes Obes Metab. 2012;14(6):539-45.

12. Dietrich E, Powell J, Taylor JR. Canagliflozin: a novel treatment option for type 2 diabetes. Drug Des Devel Ther. 2013;7:1399-408.

13. Stenlof K, Cefalu WT, Kim KA, et al. Efficacy and safety of canagliflozin monotherapy in subjects with type 2 diabetes mellitus inadequately controlled with diet and exercise. Diabetes Obes Metab. 2013;15(4):372-82.

14. Stenlof K, Cefalu WT, Kim KA, et al. Long-term efficacy and safety of canagliflozin monotherapy in patients with type 2 diabetes inadequately controlled with diet and exercise: findings from the 52-week CANTATA-M study. Curr Med Res Opin. 2014;30(2):163-75.

15. Cefalu WT, Leiter LA, Yoon KH, et al. Efficacy and safety of canagliflozin versus glimepiride in patients with type 2 diabetes inadequately controlled with metformin (CANTATA-SU): 52 week results from a randomised, double-blind, phase 3 non-inferiority trial. Lancet. 2013;382(9896):941-50.

16. Schernthaner G, Gross JL, Rosenstock J, et al. Canagliflozin compared with sitagliptin for patients with type 2 diabetes who do not have adequate glycemic control with metformin plus sulfonylurea: a 52-week randomized trial. Diabetes Care. 2013;36(9):2508-15.

17. Bode B, Stenlof K, Sullivan D, Fung A, Usiskin K. Efficacy and safety of canagliflozin treatment in older subjects with type 2 diabetes mellitus: a randomized trial. Hosp Pract (1995). 2013;41(2):72-84.
18. FARXIGA (dapagliflozin) tablets, for oral use. Bristol-Meyers Squibb. Revised January 2014. Available at: http://wwwl.astrazeneca-us.com/pi/ pi_farxiga.pdf. Accessed October 22, 2015.

19. JARDIANCE (empagliflozin) tablets, for oral use. Boehringer-Ingelheim. Revised June 2015. Available at: http://docs.boehringer-ingelheim.com/ Prescribing\%20Information/PIs/Jardiance/jardiance.pdf. Accessed October 22, 2015.

20. Davis CS, Fleming JW, Warrington LE. Sodium glucose co-transporter 2 inhibitors: a novel approach to the management of type 2 diabetes mellitus. J Am Assoc Nurse Pract. 2014;26(7):356-63.

21. Stein P, Berg JK, Morrow L, et al. Canagliflozin, a sodium glucose cotransporter 2 inhibitor, reduces post-meal glucose excursion in patients with type 2 diabetes by a non-renal mechanism: results of a randomized trial. Metabolism. 2014;63(10):1296-303.

22. Tahrani AA, Barnett AH, Bailey CJ. SGLT inhibitors in management of diabetes. Lancet Diabetes Endocrinol. 2013;1(2):140-51.

23. Clar C, Gill JA, Court R, Waugh N. Systematic review of SGLT2 receptor inhibitors in dual or triple therapy in type 2 diabetes. BMJ Open. 2012;2(5):e001007.

24. JANUVIA (sitaglipitin) tablets. Merck \& Co. Revised August 2015. Available at: http://www.merck.com/product/usa/pi_circulars/j/januvia/ januvia_pi.pdf. Accessed October 22, 2015.

25. Karagiannis T, Paschos P, Paletas K, Matthews DR, Tsapas A. Dipeptidyl peptidase- 4 inhibitors for treatment of type 2 diabetes mellitus in the clinical setting: systematic review and meta-analysis. BMJ. 2012;344:e1369.

26. Ginde AA, Blanc PG, Lieberman RM, Camargo CA Jr. Validation of ICD9-CM coding algorithm for improved identification of hypoglycemia visits. BMC Endocr Disord. 2008;8:4.

27. Quan H, Sundararajan V, Halfon P, et al. Coding algorithms for defining comorbidities in ICD-9-CM and ICD-10 administrative data. Med Care. 2005;43(11):1130-39.

28. Levey AS, Stevens LA, Schmid CH, et al. A new equation to estimate glomerular filtration rate. Ann Intern Med. 2009;150(9):604-12.

29. U.S. Bureau of Labor Statistics. Consumer Price Index (CPI) for medical care. Available at: http://data.bls.gov/cgi-bin/surveymost?cu. Series name: CUUR0000SAM. Accessed November 3, 2015.

30. Buysman EK, Chow W, Henry H, Rupnow MF. Characteristics and short-term outcomes of patients with type 2 diabetes mellitus treated with canagliflozin in a real-world setting. Curr Med Res Opin. 2015;31(1):137-43.

31. Grabner M, Chu J, Raparla S, Quimbo R, Zhou S, Conoshenti J. Clinical and economic outcomes among patients with diabetes mellitus initiating insulin glargine pen versus vial. Postgrad Med. 2013;125(3):204-13.

32. Xie L, Zhou S, Wei W, Gill J, Pan C, Baser O. Does pen help? A realworld outcomes study of switching from vial to disposable pen among insulin glargine-treated patients with type 2 diabetes mellitus. Diabetes Technol Ther. 2013;15(3):230-36. 


\section{APPENDIX A ICD-9-CM Codes Used for Exclusion Criteria and Comorbidities}

\begin{tabular}{l|l}
\hline Condition & \multicolumn{1}{c}{ ICD-9-CM Code } \\
\hline Type l diabetes & $250 . \mathrm{xl}, 250 . \mathrm{x} 3$ \\
\hline Gestational diabetes & $648.8 \mathrm{x}$ \\
\hline Hyperglycemia not other specified & $790.6 \mathrm{x}$ \\
\hline Neonatal diabetes mellitus & $775.1 \mathrm{x}$ \\
\hline Nonclinical diabetes & 790.29 \\
\hline Diabetes with hyperosmolar coma & $250.2 \mathrm{x}$ \\
\hline Neuropathy & $250.6 \mathrm{x}, 707.1 \mathrm{x}, 892.1,785.4,040.0$ \\
\hline Nephropathy & $250.4 \mathrm{x}$ \\
\hline Retinopathy & $250.5 \mathrm{x}, 362.0 \mathrm{x}, 366.41$ \\
\hline Gastrointestinal disease & $536.8,536.3,536.4 \mathrm{x}, 787.01,780.02,787.03,787.3,789.0 \mathrm{x}, 564.0,564.01,564.02,564.03,564.09,787.91$ \\
\hline Dyslipidemia & $272 . \mathrm{xx}$ \\
\hline Hypertension & $401 . \mathrm{x}, 402 . \mathrm{xx}, 403 . \mathrm{xx}, 404 . \mathrm{xx}, 405 . \mathrm{xx}, 437.2$ \\
\hline Obesity & $278.0 \mathrm{x}, \mathrm{V} 85.3, \mathrm{~V} 85.4$ \\
\hline ICD-9-CM=International Classification of Diseases, Ninth Revision, Clinical Modification.
\end{tabular}

\section{APPENDIX B All-Cause Utilization and Costs} at Baseline

\begin{tabular}{|c|c|c|c|c|c|}
\hline & \multirow{2}{*}{\multicolumn{2}{|c|}{$\begin{array}{c}\begin{array}{c}\text { Canagliflozin } \\
\text { Initiators }\end{array} \\
\mathrm{N}=1,566 \\
\end{array}$}} & \multirow{2}{*}{\multicolumn{2}{|c|}{$\begin{array}{c}\begin{array}{c}\mathrm{DPP}-4 \\
\text { Initiators }\end{array} \\
\mathrm{N}=26,224 \\
\end{array}$}} & \multirow{3}{*}{$\begin{array}{c}P \\
\text { Value }^{\mathrm{a}}\end{array}$} \\
\hline & & & & & \\
\hline & $\mathrm{N}$ & $\%$ & $\mathrm{~N}$ & $\%$ & \\
\hline \multicolumn{6}{|l|}{ Annual health care utilization } \\
\hline Office visits, with $\geq 1$ visit & 1,548 & 98.9 & 25,574 & 97.5 & $<0.001$ \\
\hline Office visits, mean (SD) & 7.1 & 6.1 & 6.4 & 5.6 & $<0.001$ \\
\hline Endocrinologist visits, with $\geq 1$ visit ${ }^{b}$ & 444 & 28.4 & 2,260 & 8.6 & $<0.001$ \\
\hline Endocrinologist visits, mean (SD) ${ }^{\mathrm{b}}$ & 0.7 & 1.3 & 0.2 & 0.8 & $<0.001$ \\
\hline Other outpatient visits, with $\geq 1$ visit $^{c}$ & 1,509 & 96.4 & 24,792 & 94.5 & 0.002 \\
\hline Other outpatient visits, mean (SD)c & 7.7 & 8.4 & 7.3 & 9.4 & 0.129 \\
\hline Emergency room visits, with $\geq 1$ visit & 252 & 16.1 & 3,845 & 14.7 & 0.121 \\
\hline Emergency room visits, mean (SD) & 0.2 & 0.6 & 0.2 & 0.6 & 0.391 \\
\hline Inpatient visits, with $\geq 1$ visit & 123 & 7.9 & 2,626 & 10.0 & 0.005 \\
\hline Inpatient visits, mean (SD) & 0.1 & 0.4 & 0.1 & 0.5 & 0.010 \\
\hline \multicolumn{6}{|l|}{ Annual pharmacy utilization } \\
\hline Pharmacy dispensing, with $\geq 1$ fill & 1,557 & 99.4 & 25,727 & 98.1 & $<0.001$ \\
\hline Pharmacy dispensing, mean (SD) & 29.6 & 17.0 & 20.9 & 15.2 & $<0.001$ \\
\hline \multicolumn{6}{|c|}{ Annual health care costs per patient, 2013 USD } \\
\hline Office visits, mean (SD) & 1,025 & 2,841 & 930 & 1,750 & 0.045 \\
\hline Other outpatient visits, mean (SD) & 2,809 & 7,749 & 3,033 & 10,038 & 0.386 \\
\hline Emergency room visits, mean (SD) & 355 & 1,266 & 317 & 1,275 & 0.255 \\
\hline Inpatient visits, mean (SD) & 1,943 & 14,916 & 2,681 & 15,143 & 0.057 \\
\hline Total medical costs, mean (SD) & 6,131 & 18,991 & 6,961 & 20,269 & 0.114 \\
\hline Total medical costs, median & 1,970 & - & 1,757 & - & - \\
\hline Pharmacy costs, mean (SD) & 6,457 & 13,538 & 3,445 & 5,138 & $<0.001$ \\
\hline Pharmacy costs, median & 4,791 & - & 2,221 & - & - \\
\hline $\begin{array}{l}\text { Total medical + pharmacy costs, } \\
\text { mean (SD) }\end{array}$ & 12,588 & 23,957 & 10,406 & 21,602 & $<0.001$ \\
\hline $\begin{array}{l}\text { Total medical + pharmacy costs, } \\
\text { median }\end{array}$ & 7,812 & - & 5,009 & - & - \\
\hline
\end{tabular}

ap values are from two-sample t-tests for continuous variables and from chi-square tests for categorical variables.

${ }^{b}$ Endocrinologist visits that take place in an office setting.

'Other outpatient facility visits such as clinic, ordered lab tests, etc.

DPP-4 = dipeptidyl peptidase-4; SD=standard deviation; $U S D=U . S$. dollars . 